\title{
Carbon management strategies in manufacturing companies: An exploratory note*
}

\author{
Simon Čadež, Albert Czerny**
}

In order to meet the Kyoto Protocol's greenhouse gas emissions targets, the EU has implemented an Emissions Trading Scheme (EU ETS) as a cornerstone of its climate policy. The main attribute of this mechanism is its inherent flexibility. It offers companies the possibility of tailoring a carbon management strategy that is the most cost-effective, i.e. reducing actual emissions vs. buying allowances to emit. Although the EU ETS was launched in 2005, to date little is known about its implications for corporate carbon management. The study provides some original insights into corporate carbon management strategies by deploying a case study of two Slovenian manufacturing companies.

Um die Ziele des Kyoto-Protokolls bezüglich Treibhausgasemissionen zu erreichen, hat die EU ein Emissionshandelsschema (EUETS) als Eckstein seiner Klimapolitik eingeführt. Die wichtigste Eigenschaft dieses Mechanismus ist die inherente Flexibilität. Es bietet den Unternehmen die Möglichkeit der Anpassung ihrer Kohlenstoffmanagement-Strategie, das heisst die Verringerung der tatsächlichen Emissionen oder der Kauf von entsprechenden Zertifikaten. Obwohl die EUETS im Jahr 2005 eingeführt wurde, ist bis heute nur wenig über ihre Bedeutung für das betriebliche Kohlenstoffmanagement bekannt. Diese Studie liefert einige Einblicke in betriebliche Kohlenstoffmanagement-Strategie anhand einer Fallstudie von zwei slowenischen Industrieunternehmen.

Keywords: Carbon management, Strategy, EU Emissions Trading Scheme, Carbon efficiency, Slovenia

* Manuscript received: 18.08.10, accepted: 21.09 .10 (1 revision)

** Simon Čadež, Prof., Faculty of Economics, University of Ljubljana, Slovenia. Main research interests: Strategic management, environmental management and transition economies. Corresponding address: simon.cadez@ef.uni-lj.si.

Albert Czerny, Research Fellow, Faculty of Economics, University of Ljubljana, Slovenia. Main research interests: Environmental management and transition economies. 


\section{Introduction}

In order to avoid the potentially catastrophic outcomes of global warming (IPCC 2007; Stern 2007), at the 3rd Conference of the Parties to the United Nations Framework Convention on Climate Change in 1997 the Kyoto Protocol was signed, providing binding measures for the reduction of greenhouse gas emissions in developed countries (Jaehn/Letmathe, 2010). The Kyoto Protocol contains three so-called flexible mechanisms to meet the national reduction commitments: (1) emissions trading; (2) a clean development mechanism; and (3) joint implementation (Braun 2009; MacKenzie 2009).

The EU Emissions Trading Scheme (EU ETS) is a cornerstone of the European Union's climate policy and started operating in 2005. It encompasses about 11,500 installations from energy and industry sectors that are responsible for about $40 \%$ of greenhouse gas emissions in the EU (Braun 2009). The EU ETS is organised in three phases. Phase 1 from 2005 to 2007 provided many companies and national administrations with a period of learning about the options and problems of this new policy tool (Convery et al. 2008; Engels 2009). Phase 2 from 2008 to 2012 is congruent with the compliance period of the Kyoto Protocol in which the EU as a whole has agreed to a reduction commitment of minus 8\% compared to the base year 1990 (Braun 2009; Engels 2009). Phase 3 will start in 2013 and run for eight years.

The EU ETS gives companies included in the scheme flexibility in meeting their reduction commitments. Each entity can either reduce actual greenhouse gas emissions or purchase allowances to emit. This flexibility offers companies the possibility of tailoring a strategy that is the most cost-effective (Sandoff/Schaad 2009) and hence an effective carbon management strategy is a potential intangible source of a competitive advantage (Aver/Cadez 2010; Cater/Cater 2009; Okereke 2007; Porter/Reinhardt 2007). Empirical evidence shows that organisational responses to this common policy tool differ (Anger/Oberndorfer 2008; Engels et al. 2008; Engels 2009, Okereke 2007; Sandoff/Schaad 2009). Yet the bulk of this evidence is limited to emissions trading strategies, whereas we know very little about corporate carbon management strategies in terms of a balance between actual emissions reductions and emissions trading.

This study's main aim is to provide insights into corporate carbon management strategies in manufacturing companies. Given the nascent state of knowledge about this phenomenon, the study is bound to be exploratory and hence a case study method was chosen (Eisenhardt 1989; Yin 2009). For comparative purposes, the case study involved the scrutiny of two Slovenian manufacturing companies included in the scheme. The study is focussed on four aspects of their carbon management: (1) organisational learning about the EU ETS and carbon mitigation options; (2) corporate carbon management strategies for compliance with the EU ETS; (3) emissions reduction measures taken; and (4) emissions trading strategies deployed. 
The remainder of the paper is organised as follows. In the next section the main characteristics of the EU ETS are outlined, including its implications for companies. Following this, the research methodology is presented and the findings are revealed. A discussion and conclusion are provided in the final section, together with a number of pointers for future research.

\section{The EU Emissions Trading Scheme and its implications for companies}

The EU ETS, a "cap and trade" system as provided for in the Kyoto Protocol imposes national caps on emissions of greenhouse gases. Under the EU ETS, a government allocates or auctions allowances based on some assessment of normal emissions to the system's participants or entities (Cook 2009). Each emission allowance entitles the entity to emit one ton of $\mathrm{CO} 2$ equivalent per annum. At the end of the year, the entity must surrender the emission allowances corresponding to the extent of its emissions (Jaehn/Letmathe 2010). The number of emission allowances within the EU ETS is fixed. In the case of the paucity of allowances some entities have to achieve a net emissions reduction in order to provide the supply of emission allowances in the market. Assuming a perfect market and complete information, this instrument ensures that reductions are achieved most cost-effectively (Braun 2009).

The inherent flexibility of the emissions trading mechanism allows companies to develop effective environmental strategies to sustain their competitiveness (Cater/Cater 2009; Okereke 2007; Porter/Reinhardt 2007). Yet the development of an effective carbon management strategy in a turbulent environment is not simple (Gurkov 2009; Heyder/Theuvsen 2008; Karhunen 2008). It entails contemplating a variety of risk factors (Biloslavo/Friedl 2009; NiederhutBollmann/Theuvsen 2008; Trkman/McKormack 2009) such as future movements of fuel prices, potential regulatory changes, technological options, or financing and taxation issues. The development of such a strategy is further complicated because many carbon alleviation strategies require large capital expenditures and long lead times for their execution (Sandoff/Schaad 2009). In addition, each company's environmental strategy should mesh with the overall strategy (Porter/Reinhardt 2007). Relevant information and knowledge capabilities are essential in order to cope with this complexity (Cadez/Guilding, 2008; Trkman/Trkman 2009), although Engel et al. (2008) warn that the integrated methods to support these decisions are still in a state of infancy.

Assuming the scarcity of emission allowances, companies included in the scheme basically have five strategies available to help them comply: (1) reducing emissions to target; (2) buying emission allowances; (3) combining strategies 1 and 2; (4) reducing emissions below target and selling excess allowances; and (5) lowering output or discontinuing operations. Since the last option is usually not desired, this means that each company must make two 
types of informed decisions. First, companies need to decide on the balance between their $\mathrm{CO} 2$ reduction and trading of allowances. Second, companies must make decisions about actual measures for $\mathrm{CO} 2$ reduction and/or allowance trading strategies. If the scarcity of allowances is not enforced, the system would not be functional as there would be no incentive to reduce emissions and the allowances would be worthless (Hentrich et al. 2009). This was the case in phase 1 from 2005 to 2007 when the number of allowances allocated exceeded the actual emissions by 4\% (Anger/Oberndorfer 2008; Ellerman/Buchner 2007). As the allowances were not transferable to period 2, the release of this information in April 2006 resulted in the diminution of their value to a penny stock (Jaehn/Letmathe 2010).

The available emission mitigation measures depend on the nature of emissions. The most common in the manufacturing sector are combustion emissions which occur as a result of burning fossil fuels (MacKenzie, 2009). For combustion emissions, a range of reduction options are available, such as (IPCC 2007): (1) fuel switching (i.e. coal to natural gas); (2) increased boiler efficiency; (3) renewable heat and power (i.e. hydro, solar, nuclear, geothermal); and (4) early applications of $\mathrm{CO} 2$ capture and storage.

Analogous to the wide array of emission mitigation options companies can also pursue a range of emissions trading strategies. Passive strategies entail mere compliance with the EU ETS, i.e. purchasing allowances in the case of a shortfall or selling allowances in the case of a surplus. By contrast, active strategies imply active trading with the allowances with the aim to secure profit via trading activities.

Following the above discussion, in this study we are primarily interested in the following aspects of corporate carbon management:

1. Organisational learning about the EU ETS and carbon mitigation options.

2. Carbon management strategies deployed to comply with the EU ETS in terms of a balance between emissions reductions and emissions trading.

3. Emissions reduction measures taken.

4. Emissions trading strategies deployed.

\section{Research design and methodology}

Given the exploratory nature of the study a multiple-case study method was deployed. A case study is the preferred methodology for building knowledge about a phenomenon when existing knowledge is scant (Eisenhardt 1989; Yin 2009). Observations in this study are based on an examination of two Slovenian manufacturing companies. Slovenia makes a good sample because it is the only Eastern European country in which emissions scarcity was enforced already in phase 1 (Ellerman/Buchner 2007; Markovic-Hribernik/Murks 2007). 
The selected companies were drawn from the National Allocation Plan (NAP) for Slovenia. The NAP for phase 2 comprises 96 installations and of these 78 come from the manufacturing sector. For comparative reasons, we aimed to select companies from a similar industry and with a similar nature of emissions (Aristovnik/Seljak 2010). Further, following Eisenhardt's (1989) suggestion to choose cases that represent polar types in which the process of interest is transparent, we decided to select one company with excess emissions (net short with allowances) and one company with excess allowances (net long with allowances) in phase 1. Two companies that meet these criteria were identified in the chemical manufacturing industry where only combustion emissions occur. A brief description of the selected companies is provided in Table 1 and the next paragraph.

Table 1. A brief description of the case companies

\begin{tabular}{|c|c|c|c|c|c|}
\hline Company & Industry & $\begin{array}{c}\text { Revenues } \\
2008 \text { in } € \\
\text { million }\end{array}$ & $\begin{array}{c}\text { Staff } \\
2008\end{array}$ & Ownership & $\begin{array}{c}\text { Allowanc } \\
\text { es status } \\
\text { in phase 1 }\end{array}$ \\
\hline Cinkarna & Chemicals manufacturing & 131 & 1.100 & Private & Net short \\
\hline Krka & $\begin{array}{c}\text { Chemicals/pharma } \\
\text { manufacturing }\end{array}$ & 950 & 7.500 & Private & Net long \\
\hline
\end{tabular}

Cinkarna is a manufacturer of chemicals. Its main product is titanium dioxide in two major commercial forms: the traditional - and quantity-wise essential production of pigment grade, and the innovative ultra-fine or nano grade, which is increasingly being utilised in modern technologies. About $90 \%$ of its production is being exported. Krka is a manufacturer of chemicals and pharmaceuticals. Its main products are pharmaceuticals, animal health products, cosmetics, and other chemicals. Krka also exports about $90 \%$ of its total production.

The findings of the study are based on both qualitative and quantitative data. The qualitative data were obtained via interviews conducted in the two selected companies. Both companies have an energy department which is responsible for carbon management and thus the interviews were conducted with the heads of the energy department. As a means of validating the interviews, we also collected some hard data on allowances allocation, actual emissions, and corporate output that were available from the Agency for Environment of the Republic and Slovenia and from corporate annual reports.

\section{Analysis of the cases}

The four aspects of corporate carbon management are discussed in turn. 


\section{Organisational learning about the EU ETS and carbon mitigation options}

It is noteworthy that both companies believe that they know the concept and institutional framework of the EU ETS very well, including the anticipated changes to the scheme in phase 3 . Knowledge regarding emissions trading was accumulated via different sources prior to actual introduction of the EU ETS. The prime source of information was government entities, although the EU ETS participants also exchanged information directly with each other. Further, they have been regularly contacted by specialised allowances brokers who continuously inform them about EU ETS market developments. After the introduction of the scheme there were some starting problems but the experience soon began to accumulate and after 5 years it appears that the EU ETS is becoming a mature market. At Cinkarna, they even claim that they are actively involved in the future design and legislative framework of the EU ETS (see the comment below).

"We have to compliment our cooperation with the Ministry of the Environment and Spatial Planning. They are giving us an opportunity to suggest improvements and actively participate in the future design of the scheme." (Cinkarna)

Knowledge about emissions mitigation options also started to accumulate prior to actual introduction of the scheme. Somewhat remarkably, at Krka they claim that the bulk of this knowledge was acquired well before the scheme was introduced (see the comment below).

"Our company has always been environmentally conscious. We gained the bulk of our knowledge regarding emissions reduction options well before the actual implementation of the EU ETS. (Krka)

\section{Corporate compliance strategies}

Both companies indicated that the introduction of the EU ETS in 2005 provided an incentive for actual emissions reductions. The comments below briefly summarise their carbon management strategies.

"Since the introduction of the EU ETS we have accumulated lots of knowledge and we are gradually improving all business processes in order to save energy and reduce emissions. This represents a double saving: we are reducing our energy costs and we don't need to buy allowances. The savings are in fact quite substantial as in our company energy costs represent an important fraction of the total cost... In phase 1 we were also buying allowances due to an allowances shortfall... We cannot afford high costs for allowances if we wish to stay competitive with the prices of our products, especially vis-à-vis companies from third countries where such schemes do not exist... In phase 2 we have a surplus of allowances due to more efficient energy use..." (Cinkarna) 
"We operated with the best available technology (BAT) before the introduction of the EU ETS and our system has more or less been improved to the optimum... So far we haven't had any problems with excess emissions and we also haven't been trading with emission allowances... We find the trading too risky considering the potential returns..." (Krka)

These comments seem to confirm the anticipation that the carbon management strategy depends on the initial allocation of allowances. In Krka, with a net overallocation of allowances, no significant action regarding emissions has been taken (nor required) since the inception of the EU ETS. Cinkarna, on the other hand, with a net under-allocation of allowances, despite its articulated efforts to reduce emissions, was compelled to buy additional allowances in order to comply with the scheme in phase 1 . In order to further scrutinise these statements, Table 2 contains actual data on the allocation of allowances and actual emissions in the 2005-2009 period for the two companies.

Table 2. Allowances allocation and actual emissions in the case companies in the 2005-2009 period

\begin{tabular}{|c|c|c|c|c|c|c|c|c|}
\hline Company & $\begin{array}{c}\text { Average } \\
\text { annual } \\
\text { allowances } \\
\text { allocation } \\
\text { in phase 1 }\end{array}$ & $\begin{array}{c}\text { Actual } \\
\text { emissions } \\
2005\end{array}$ & $\begin{array}{c}\text { Actual } \\
\text { emissions } \\
2006\end{array}$ & $\begin{array}{c}\text { Actual } \\
\text { emissions } \\
2007\end{array}$ & $\begin{array}{c}\text { Actual } \\
\text { emissions } \\
2008\end{array}$ & $\begin{array}{c}\text { Actual } \\
\text { emissions } \\
2009\end{array}$ & $\begin{array}{c}\text { Index } \\
\text { actual } \\
\text { emissions } \\
09 / 05\end{array}$ & $\begin{array}{c}\text { Output* } \\
\text { normed } \\
\text { emissions } \\
\text { index } \\
09 / 05\end{array}$ \\
\hline Cinkarna & 30,577 & 31,780 & 33,631 & 31,737 & 25,295 & 24,605 & 77.4 & 73.9 \\
\hline Krka & 22,464 & 21,611 & 21,215 & 21,963 & 20,996 & 21,344 & 98.8 & 56.3 \\
\hline
\end{tabular}

*Output is measured in terms of operating revenues.

Sources: National Allocation Plan (2004/2007) and annual reports of the Agency for Environment of the Republic of Slovenia for 2005-2009.

As Table 2 shows, Cinkarna had problems with excess emissions in phase 1 (2005-2007). Yet in 2008 its emissions fell significantly, i.e. $-20.3 \%$ relative to 2007. While this indicates improved carbon efficiency, such a conclusion would be premature without taking the respective change in output into consideration. As it turns out, the respective change in operating revenues is $-16.1 \%$ and hence the bulk of the emissions reduction is to be attributed to the financial crisis and the consequent decline in output rather than improved carbon efficiency. The same holds for the whole five-year period as the actual emissions index and output normed emissions index (see the last two columns in Table 2) are almost identical.

In contrast, Krka had very stable emissions throughout the whole five-year period. While one could argue that this indicates no improvement in carbon efficiency, this is indeed not the case. Namely, in the same period, Krka almost doubled its output, yet still managed to maintain emissions at close to the original level, indicating high relative carbon efficiency. 


\section{Actual emissions reduction measures taken}

Cinkarna's strategy is to reduce emissions through higher energy efficiency (see the comment below).

"We are reducing emissions with the more efficient use of energy. For example, the "efficient use of energy" project in 2008 resulted in a $22 \%$ decrease in electricity use in a single year." (Cinkarna)

On the other hand, Krka claims that it had optimised its facilities before the scheme was introduced and that, with the current state of technology, there is very little scope for further improvement (see the comment below).

"We had switched to state-of-the-art steam boilers before the introduction of the scheme. These operate at maximum efficiency, we also re-use wastewater. We are already using natural gas as an energy source, hence the only option to further reduce emissions is to introduce solar panels. This is however close to impossible with the current state of technology due to the sheer size of our manufacturing complex and also because the installation is running non-stop." (Krka)

Both of these assertions seem to be consistent with the data presented in Table 2. However, it should be again noted that the bulk of the decrease of electricity use at Cinkarna is likely attributable to the decline in output rather than considerably improved energy efficiency.

\section{Emissions trading strategies deployed}

As outlined before, Krka has no experience in emissions trading. If it will require additional allowances in the future it intends to buy them in the market. While Cinkarna has engaged in emissions trading, so far it has only been buying additional allowances to make up for its excess emissions in phase 1 (see the comment below).

"In phase 1 we bought allowances due to a shortfall in allowances. We bought allowances directly from other companies in order to avoid brokerage and other transaction costs... In our view, the biggest problem of trading is proper timing as the price of allowances is highly volatile... In phase 2 we have a surplus of allowances and we are thus planning to sell the spare allowances. Now we are waiting for profitable market conditions..." (Cinkarna)

\section{Discussion and conclusion}

While literature about corporate carbon management within the EU ETS setting is beginning to emerge (Anger/Oberndorfer 2008; Engels et al. 2008; Engels 2009; Okereke 2007; Sandoff/Schaad 2009), this literature predominantly focuses on corporate emission trading practices. The main contribution of this study can be seen in its deployment of a more holistic approach to investigating 
carbon management strategies in terms of a balance between actual emissions reductions and emissions trading.

The two companies examined in this study had accumulated a significant amount of knowledge about emissions trading and emissions mitigation options before the scheme was actually introduced. The prime sources of advice about the EU ETS policy tool were Slovenian government entities, other Slovenian EU ETS participants and specialised allowances brokers. This finding is relatively inconsistent with Engels et al. (2008) and Engels (2009) who provide a comparison of how companies in four old EU member states had learned about this policy tool. In Germany and the UK they primarily relied on specialised private consulting firms, in the Netherlands the most important source of advice was workshops, whereas in Denmark many companies did not use any form of external advice at all.

The companies considered here appear to pursue very different carbon management strategies. Cinkarna, net short with allowances in phase 1, has practised a combined strategy of reducing emissions and buying additional allowances to comply with the scheme. In phase 2 it has substantially reduced its emissions so it can now sell excess allowances. Yet it should be noted that the bulk of the reduction in phase 2 can be attributed to a decline of output in the current period of financial crisis rather than improved carbon efficiency. Conversely, Krka was net long with allowances in both phases. Its total emissions are relatively stable throughout the whole period; however, when taking the change in its output into account it has substantially improved its carbon efficiency. Krka has not engaged in any emissions trading which is consistent with the premise that companies with a net over-allocation of allowances are not forced to take any compliance action, although it should be noted that Krka operated with the best available technology already before the scheme was introduced. The carbon management strategies in both companies can be portrayed as relatively pragmatic with little reliance on formalised decision-making procedures. This is consistent with the view of Enger et al. (2008) that transparent and integrated methods for decision support to control carbon efficiency are not yet available.

The actual measures both companies have taken to mitigate combustion emissions are not very radical. The companies still mainly rely on fossil fuels as a source of energy but aim to maximise the carbon efficiency of the combustion processes with more traditional methods, such as fuel switching, installing highly efficient boilers and the re-use of wastewater. The companies also warn that after having implemented the best available technology the potential for a further reduction is very limited, if not impossible. This finding is consistent with Kranjcevic (2007) who contends that with the current state of technology mitigation options in the manufacturing sector are very limited, unlike in the 
energy sector where greater scope for improvement is available (Hoffmann 2007; Markovic-Hribernik/Murks 2007).

The trading strategies of the appraised companies can be characterised, at best, as passive. While Krka has not engaged in any trading at all, Cinkarna has so far only been buying additional allowances to make up for its excess emissions in phase 1. These findings are largely consistent with Engels (2009), Engels et al. (2008) and Sandoff and Schaad (2009). Engels (2009), for example, reports trading rates for four old EU member states in phase 1 which, with the exception of the Netherlands, are about around $50 \%$ or below (in other words, about half of EU ETS participants from Denmark, Germany and the UK have not traded at all). Further, Engels et al. (2008) reveal that most companies in these same four countries have only acted as either buyers or sellers, thereby implying a passive strategy. Finally, Sandoff and Schaad (2009) point to the similar behaviour of Swedish EU ETS participants where only a few companies have shown an active interest in the market.

From the practitioner's point of view, implications of this study arise from the assertion to build a competitive advantage on intangible sources (Aver/Cadez 2009; Cater/Cater 2009), such as effective carbon management strategies (Okereke 2007; Porter/Reinhardt 2007). The companies pointed out that buying allowances represents a significant cost which deteriorates either their profitability if they refuse to raise product prices or their competitiveness if they do raise product prices. As a result, reducing combustion emissions represents a double saving - reduced energy costs and reduced allowances costs. This observation is consistent with the ecoefficiency theory. While the traditional view argues that improving environmental performance inevitably leads to higher costs and lower productivity, thereby eroding corporate competitiveness (Porter/Van der Linde 1995), the advocates of the recent ecoefficiency theory provide evidence that it is possible to reduce costs and improve productivity while simultaneously improving environmental performance (Burnett/Hansen 2008; King/Lenox 2002). However, it should be noted that the potential for reduction is very limited with the current state of technology if companies continue to use fossil fuels as a prime source of energy (Kranjcevic 2007). More radical improvements in carbon efficiency are only attainable if fossil fuels are abandoned and replaced with other energy sources.

The study herein offers a number of useful pointers for future research. One such venue would be to conduct a more in-depth investigation of actual corporate decision-making procedures regarding carbon management and identify key financial and non-financial factors that are being considered when making such decisions. Another issue worthy of further enquiry revolves around the role of cost-effectiveness in designing environmental strategies. We know very little about how this factor is being incorporated in corporate decision- 
making processes, even though it is regarded as the most important property of the emissions trading mechanism.

\section{References:}

Anger, N./Oberndorfer, U. (2008): Firm performance and employment in the EU emissions trading scheme: an empirical assessment for Germany, in: Energy Policy, 36, 12-22.

Aristovnik, A./Seljak, J. (2010): Performance budgeting in Slovenia - Lessons from international experiences and some methodological issues, in: Ekonomicky Casopis, $58,3,271-291$.

Aver, B./Cadez, S. (2009): Management accountants' participation in strategic management processes: a cross industry comparison, in: Journal for East European Management Studies, 14, 3, 310-322.

Biloslavo, R./Friedl, P. (2009): Influence factors in change methods choice and their impact on change deficiencies: A case study of construction industry in transition economy, in: Journal for East European Management Studies, 14, 3, 241-264.

Braun, M. (2009): The evolution of emissions trading in the European Union - the role of policy networks, knowledge and policy entrepreneurs, in: Accounting, Organizations and Society, 34, 469-487.

Burnett, R.D./Hansen, R.D. (2008): Ecoefficiency: defining a role for environmental cost management, in: Accounting, Organizations and Society, 33, 551-581.

Cadez, S./Guilding, C. (2008). An exploratory investigation of an integrated contingency model of strategic management accounting, in: Accounting, Organizations and Society, $33,836-863$.

Cater, T./Cater, B. (2009): (In)tangible resources as antecedents of company's competitive advantage and performance, in: Journal for East European Management Studies, 14, 2, 186-209.

Convery, F.J. (ed.) (2008): The European Carbon Market in Action: Lessons from the First Trading Period. Interim report. Dublin: UCD.

Convery, F.J. (2009): Reflections - the emerging literature on emissions trading in Europe, in: Review of Environmental Economics and Policy, 3, 121-137.

Cook, A. (2009): Emission rights: From costless activity to market operations, in: Accounting, Organisations and Society, 34, 456-468.

Eisenhardt, K. (1989): Building theories from case study research, in: Academy of Management Review, 14, 532-550.

Ellerman, D.A./Buchner, B.K. (2007): The European Union Emissions Trading Scheme: origins, allocation, and early results, in: Review of Environmental Economics and Policy, 1, 66-87.

Engel, B. (ed.) (2008): Integration of carbon efficiency into corporate decision making, in: Fleischmann, B. (ed.): Operations Research Proceedings, Berlin: Springer Verlag, 4752. 
Engels, A. (ed.) (2008): Preparing for the 'real' market: national patterns of organizational learning and company behaviour in the European Emissions Trading Scheme, in: European Environment, 18, 276-297.

Engels, A. (2009): The European Emissions Trading Scheme: an exploratory study of how companies learn to account for carbon, in: Accounting, Organizations and Society, 34, 488-498.

European Commission (2007): Establishing guidelines for the monitoring and reporting of greenhouse gas emissions pursuant to Directive 2003/87/EC of the European Parliament and of the Council. (2007, 589, EC).

European Commission (2008): The EU Emissions Trading Scheme. Accessed at: http://ec.europa.eu/environment/climat/pdf/brochures/ets_en.pdf

Gurkov, I. (2009): Strategy process as formulation and realization of corporate goals: The synthesis of surveys in Russian firms, in: Journal for East European Management Studies, 14, 1, 48-64.

Hentrich, S. (ed.) (2009): Emissions trading and competitiveness: lessons from Germany, in: Climate Policy, 9, 316-329.

Heyder, M./Theuvsen, L. (2008): Strategic management in the German brewing industry: Are there still differences between East and West?, in: Journal for East European Management Studies, 13, 1, 10-39.

Hoffmann, V. (2007): EU ETS and investment decisions: the case of the German electricity industry, in: European Management Journal, 25, 464-474.

IPCC (International Panel on Climate Change) (2007). Fourth assessment report. Climate Change 2007: Synthesis Report. Accessed at: http://www.ipcc.ch/pdf/assessmentreport/ar4/syr/ar4_syr.pdf.

Jaehn, F./Letmathe, P. (2010): The emissions trading paradox, in: European Journal of Operational Research, 202, 1, 248-254.

Karhunen, P. (2008): Toward convergence in the St. Petersburg hotel industry through the lens of institutional theory, in: Journal for East European Management Studies, 13, 2, 106-128.

King, A./Lenox, M. (2002): Exploring the locus of profitable pollution reduction, in: Management Science, 48, 289-299.

Kranjcevic, E. (2007): Slovenia and its new environmental mechanisms for reduction of greenhouse gas emissions, in: Management of Environmental Quality, 18, 61-70.

MacKenzie, D. (2009): Making things the same: Gases, emission rights and the Politics of the Carbon Markets, in: Accounting, Organizations and Society, 34, 440-455.

Markovic Hribernik, T./Murks, A. (2007): Slovenia's climate policy efforts: CO2 tax and implementation of EU ETS, in: Climate policy, 7, 2, 139-155.

Niederhut-Bollman, C./Theuvsen, L. (2008): Strategic management in turbulent markets: The case of the German and Croatian brewing industries, in: Journal for East European Management Studies, 13, 1, 63-88.

Okereke, C. (2007): An exploration of motivation, drivers and barriers to carbon management: the FTSE 100, in: European Management Journal, 25, 475-486. 
Porter, M.E./Van der Linde, C. (1995): Green or competitive: ending the stalemate, in: Harvard Business Review, 73, 120-134.

Porter, M.E./Reinhardt, F.L. (2007): Grist: A strategic approach to climate, in: Harvard Business Review, 85, 22-26.

Sandoff, A./Schaad,G. (2009): Does EU ETS lead to emission reductions through trade? The case of the Swedish emissions trading sector participants, in: Energy Policy, 37, 39673977.

Stern, N. (2007): The economics of climate change - The Stern review. Cambridge: Cambridge University Press.

Trkman, P./McKormack, K. (2009): Supply chain risk in turbulent environments - A conceptual model for managing supply chain network risk, in: International Journal of Production Economics, 119, 247-258.

Trkman, M./Trkman P. (2009): A wiki as intranet: a critical analysis using the Delone and McLean model, in: Online Information Review, 33, 1087-1102.

Yin, R.K. (2009): Case study research: design and methods. Thousand Oaks: Sage Publications. 